\title{
A ORIENTAÇÃO DOS INSPETORES ESCOLARES NA FORMAÇÃO DE PROFESSORES NO PERÍODO DE 1970 A 1976: UM OLHAR SOBRE SÃO PAULO
}

\author{
LA ORIENTACIÓN DE LOS INSPECTORES ESCOLARES EN LA FORMACIÓN DE \\ PROFESORES EN EL PERÍODO DE 1970 HASTA 1976: UNA MIRADA SOBRE SÃO \\ PAULO
}

\section{SCHOOL INSPECTORS GUIDANCE ON TEACHER'S EDUCATION FROM 1970 TO 1976: A LOOK OVER SÃO PAULO}

\author{
Raquel Lazzari Leite BARBOSA ${ }^{1}$ \\ Rosemary Trabold NICACIO ${ }^{2}$
}

\begin{abstract}
RESUMO: Este artigo discute as práticas de formação de professores das escolas isoladas do município de Assis, Estado de São Paulo, no período de 1970 a 1976. Essa formação era conduzida pelos inspetores escolares que contavam com apoio do Serviço de Orientação Pedagógica do estado. Este trabalho é resultado de uma pesquisa documental, na perspectiva transnacional da história da educação que analisou as práticas de formação docente por meio dos discursos registrados nas atas de reuniões pedagógicas. Os inspetores tinham sob sua responsabilidade a orientação e a físcalização na implantação de um currículo que, supunhase, trazer ao estado melhor qualidade na educação com a erradicação da repetência no ensino primário e, também, no cumprimento das diretrizes impostas por um programa de desenvolvimento econômico assinado entre Brasil e Estados Unidos.
\end{abstract}

PALAVRAS-CHAVE: Formação de professores. Inspetores escolares. Ensino elementar. SEROP. Escolas isoladas.

RESUMEN: Este artículo discute prácticas de formación de profesores de escuelas aisladas del municipio de Assis, estado de São Paulo, en el período que comprende los años 1970 hasta 1976. Esa formación era conducida por los inspectores escolares que contaban con el Servicio de Orientación Pedagógica del estado. Este trabajo es resultado de una investigación documental, bajo la perspectiva transnacional de la historia de la educación que analizó las prácticas de formación docente utilizando los discursos registrados en las atas de reuniones pedagógicas. Los inspectores tenían bajo su responsabilidad la orientación y la fiscalización de un currículo que, se suponía, trajera al estado mejor calidad educacional con la erradicación de la repitencia en la educación primaria y, además, el cumplimiento de las directrices impuestas por un programa de desarrollo económico firmado entre Brasil y Estados Unidos.

PALABRAS CLAVE: Formación de profesores. Inspectores escolares. Enseñanza elemental. SEROP. Escuelas aisladas.

\footnotetext{
${ }^{1}$ Universidade Estadual Paulista (UNESP), Assis - SP - Brasil. Professor Adjunto do Departamento de Estudos Linguísticos, Literários e da Educação - DELLE. Doutorado em Educação (UNICAMP). ORCID: https://orcid.org/0000-0002-7688-8486. E-mail: raquel.leite@unesp.br

${ }^{2}$ Universidade Federal de Catalão (UFCAT), Catalão - GO - Brasil. Professora da Faculdade de Educação. Doutorado em Educação (UNESP). ORCID: https://orcid.org/0000-0003-1901-9265.E-mail: 
ABSTRACT: This article discusses isolated school teachers' training practices in Assis-São Paulo state from 1970 to 1976. That education was led by school inspectors with the help of state Pedagogical Guidance Service. This is a documental research with transnational approach concerning education history which analyzed teachers' education practices through speeches registered in pedagogical meeting minute. The inspectors were responsible for guiding and supervise the syllabus whose implementation would increase education quality in the state by eliminating grade failure in primary schools and meet the guidelines enforced by an economic development program signed up between Brazil and the United States of America.

KEYWORDS: Teachers' education. School inspectors. Elementary schooling. SEROP (Pedagogical Guidance Service in Portuguese). Isolated schools.

\section{Introdução}

O surgimento da escola e, posteriormente, a organização dos sistemas de ensino e políticas que tornaram obrigatória a escolarização foram investimentos fundamentais para a consolidação do país como nação dentro do ideário republicano. É possível identificar conexões e interdependências nessa organização da educação escolar em outros países, o que nos levou aos estudos em história da educação numa perspectiva transnacional, num constante movimento entre o local e o global.

A história da Educação nessa abordagem, traz a possibilidade para a análise da vida e experiências dos sujeitos, num movimento capaz de evidenciar suas múltiplas dimensões dentro desses espaços, favorecendo o trabalho do historiador com as fontes primárias (VIDAL, 2020).

Cabe destacar que esta pesquisa está vinculada ao Projeto "Saberes e Práticas em fronteiras: por uma história transnacional da educação (1810...)", vinculada à Fapesp (Processo 2018/26699-4).

Nesse artigo, nosso objetivo foi caracterizar as práticas de formação docente das escolas isoladas paulistas por meio de atas de reuniões pedagógicas e, nesse percurso, destacar seus aspectos para posterior identificação das fronteiras e territórios de uma história transnacional de educação. Essas práticas de formação eram conduzidas pelos inspetores escolares da Delegacia de Ensino Elementar de Assis entre os anos de 1970 e 1976. A escolha por esse recorte da análise local nos aproximou da educação pública estadual paulista no período em questão, uma vez que a organização da educação ocorria de forma semelhante em todas as Delegacias de Ensino Elementar do estado, além disso, esse foi um período com importantes mudanças nas políticas educacionais. 
Para compreender esse percurso, no entanto, temos que retroceder ao final do Século XIX e início do Século XX, tendo em vista a mudança significativa no papel da escola promovida pelas reformas nos modelos educacionais daquele período. Em São Paulo, o ensino primário se tornou obrigatório pela Lei $\mathrm{n}^{\mathrm{o}} 9$ de 22 de março de 1874, institucionalizando a escola pública primária e caminhando para a concretização do projeto republicano de reforma social.

$\mathrm{Na}$ busca por consolidar esse modelo de escola, capaz de difundir os valores republicanos, a educação paulista realiza reformas do ensino como a "Reforma da Instrucção Pública” em $1892^{3}$, que definia a forma de organização da escola primária e sua obrigatoriedade dos 7 aos 12 anos. Depois, em 19204, outra "Reforma da Instrucção Pública" do estado cria as Delegacias de Ensino, destacando a ampliação da responsabilidade do Estado com a expansão da escola de massa e a necessidade de estruturar a administração pública (SOUZA, 1998).

Esse modelo de escola primária vai se transformar somente com a reforma do ensino primário e secundário ocorrida com a Lei $\mathrm{n}^{\circ}$ 5.692, de 11 de agosto de 1971. E é nesse contexto de reformas educacionais, ainda dentro do período militar, que analisamos a partir da organização pedagógica as ações de formação docente realizadas pelos inspetores escolares.

\section{O cenário político e a Legislação Educacional}

As escolas primárias no início da década de 1970 estavam organizadas, no Estado de São Paulo, em grupos escolares e escolas isoladas, classificação esta com origem na Lei $n^{\circ}$ 1.579, de 19 de dezembro de 1917, que estabelecia diversas disposições sobre a "Instrucção pública do Estado" reafirmadas na reforma de 1920.

As escolas isoladas, como descreve Souza (2009) foram a base das mudanças na organização das escolas de primeiras letras do século XIX, contudo, mesmo

[...] dotadas de uma estrutura organizacional mais moderna, essas escolas com um único professor ensinando a classes de diferentes níveis de conhecimento [...], passaram a ocupar um lugar secundário no sistema de ensino primário de São Paulo, sendo desprestigiadas pelos poderes públicos e pelos professores (SOUZA, 2009, p. 148).

Nos primeiros anos do Século XX, as escolas isoladas podiam ser instaladas nas periferias das zonas urbanas, em distritos ou vilas industriais. No entanto, eram identificadas 
como escolas rurais e atendiam principalmente, alunos de bairros da zona rural, e quando funcionavam em três períodos - manhã, tarde e noite - recebiam os alunos urbanos nos cursos noturnos, sua principal característica era que um único professor conduzia uma classe em que funcionavam, concomitantemente, três graus de escolaridade, segundo Mitrulis (1993, p. 1):

[...] o primeiro, o segundo e o terceiros anos primários, com a subdivisão do primeiro ano em seções $\mathrm{A}, \mathrm{B}$ e $\mathrm{C}$ formadas segundo as dificuldades dos alunos. Essa classe assim organizada atendia de 15 a 40 alunos com a idade variável de 7 a 14 nos de idade.

Já os grupos escolares eram escolas mais bem estruturadas do que as escolas isoladas e localizavam-se nas áreas centrais das cidades, possuíam "um conjunto de classes, cada uma das quais destinada a um grupo específico de alunos de dado grau de escolaridade, atribuída a um professor" (MITRULIS, 1993, p. 1).

As Delegacias de Ensino Elementar, por sua vez, foram criadas pela Lei n ${ }^{\circ} 1750$, de 8 de dezembro de 1920 conforme descrito em seu artigo $6^{\circ}$ :

Artigo 6. ${ }^{\circ}$ - Ficam creadas 15 delegacias regionaes do Ensino e elevado a 35 o número dos inspectores escolares, uns e outros nomeados livremente pelo Governo entre professores diplomados, de reconhecida competencia.

$\S \mathbf{1 .}^{\mathbf{0}}$ - Os delegados regionaes são obrigados a residir nas sédes das respectivas regiões, e os inspectores onde lhes determinar o director geral da Instrucção Publica, podendo uns e outros ser removidos pelo Governo. [...] (SÃO PAULO, 1920).

As primeiras delegacias regionais de ensino ${ }^{5}$ foram instaladas nos municípios de Araraquara, Bauru, Botucatu, Campinas, na Capital, Casa Branca, Catanduva, Guaratinguetá, Itapetininga, Piracicaba, Ribeirão Preto, Santos, Santa Cruz do Rio Pardo, São Carlos e Taubaté. O município de Assis, de acordo com este decreto, pertencia à Delegacia Regional de Santa Cruz do Rio Pardo. A criação da "Delegacia de Ensino de Assiz"6 ocorreu pelo Decreto $\mathrm{n}^{\circ} 14.542$ de 16 de fevereiro de 1945 e tinha sob sua jurisdição as escolas dos municípios de Assis, Cândido Mota, Echaporã, Ibirarema, Lutécia, Maracaí, Palmital, Paraguaçu Paulista e Quatá.

Com o desenvolvimento e crescimento no número de matrículas houve uma ampliação das Delegacias de Ensino e, consequentemente, dos cargos de inspetoria.

${ }^{5}$ A Lei $n^{\circ} 1.750 / 1920$ foi regulamentada pelo Decreto $n^{0} 3.356$, de 31 de maio de 1921 que, em seu artigo 31, definia quais eram as cidades sede das 15 Delegacias instaladas no Estado.

${ }^{6}$ Em toda legislação encontra-se Assiz escrito com a letra $\mathrm{Z}$ no final. 
Os inspetores escolares surgiram pela Lei $\mathrm{n}^{\circ} 520$, de 26 de agosto de 1897 e pelo Decreto $\mathrm{n}^{\mathrm{o}} 1883$ de 06 de junho de 1910, foram reorganizadas as inspetorias e definidas as atribuições dos inspetores escolares, como observa-se nos artigos 18 e 19:
Artigo 18. - Incumbe ao inspector escholar: 1. ${ }^{\circ}$ Comparecer todos os dias na Directoria Geral quando não estiver em serviço determinada pelo director, afim de o auxiliar nos trabalhos que lhe forem confiados;
$2 .^{\circ}$ Visitar com frequencia as escholas da zona a seu cargo de accôrdo com as instrucções do director geral, lavrando termo de sua visita;
3. ${ }^{\circ}$ Receber queixas, reclamações e representações sobre o serviço a seu cargo, transmittindo-as ao director geral, quando não tenha competencia para as resolver;
4. ${ }^{\circ}$ Instruir os directores de grupos e professores sobre o cumprimento de seus deveres;
$5 .^{\circ}$ Guiar os directores de grupos e professores na organização technica das suas classes e na adopção da methodos e processos de ensino recommendados pelo director geral;
$6{ }^{\circ}$ Impor penas que forem de sua competencia aos directores de grupos e professores por faltas que commetterem;
7. ${ }^{\circ}$ Fazer conferencias publicas sobre assumptos que interessem ao ensino e contribuam para a educação civica do povo;
8. Inquirir dos professores a modificação que convenha introduzir no regimen escholar;
9. Enviar mensalmente ao director geral uma exposição dos serviços realizados;
10. Apresentar annualmente ao director geral um relatorio minucioso sobre o ensino na zona percorrida propondo melhoramentos e modificações que julgar conveniente introduzir no regimen escholar, manifestando sua opinião a respeito dos professores;
11. Promover, de accôrdo com as municipalidades, o serviço de estatistica escholar;
12. Propor ao director geral, fundamentando a proposta, a inclusão do nome dos professores no «Livro de Honra», da directoria geral;
13. Cumprir e fazer cumprir todas as determinações do Governo e do director geral relativas ao ensino.

Artigo 19. - A inspecção e fiscalização das Escholas Complementares do interior, bem como dos grupos escholares, escholas reunidas e isoladas, situadas nos municipios em que funccionem aquellas, ficarão a cargo de um só inspector escholar (SÃO PAULO, 1897).

Esse excerto tem como objetivo clarear como a função do inspetor já se caracterizava no início do século pela dicotomia em suas atribuições de fiscalização e orientação técnica. De acordo com Mitrulis (1993, s/p)

[...] ao lado de suas funções na estrutura administrativa, a Inspeção escolar exerceria uma outra muito mais nobre que é a de "encarnar" a legislação, não no que ela possui de letra, mas de espírito. Os Inspetores Escolares representariam os postos avançados da política educacional do Estado e do País. Historicamente, as funções com atribuição de controle surgem ao mesmo tempo em que se organizavam os sistemas de ensino. 
Como se pode ver, esse perfil serviria aos propósitos do Estado, principalmente no período militar, quando os inspetores escolares passam a ser fundamentais para a implementação da política educacional no contexto econômico desenvolvimentista marcado pela recuperação do "espírito pan-americano" com a aproximação dos Estados Unidos (SILVA JR., 1984, p. 48).

Nesse contexto, as concepções acerca do papel do inspetor passam a ser delineadas por educadores que participaram dos estágios no $\mathrm{PABAEE}^{7}$ - Programa de Assistência BrasileiroAmericano ao Ensino Elementar cujo material divulgado serviu à atualização e aperfeiçoamento profissional de muitos educadores brasileiros. Nas palavras de Silva Jr. (1984, p. 50) “o conteúdo dos cursos refletia e disseminava as concepções predominantes naquele organismo especial [...] a sua simples existência despertava [...] a condição de autoridade inconteste[...]."

Em 1974, os inspetores foram substituídos por Supervisores ${ }^{8}$, passando a constituiremse especialistas da educação e mantendo a eterna dicotomia entre a função administrativa e a função pedagógica, uma vez que a hierarquização e o conceito de controle eram fundamentais naquele período. Segundo Silva Jr. (1984, p. 48) "os resquícios do nacionaldesenvolvimentismo cultivado e cultuados pelo ISEB $^{9}$ [Instituto Superior de Estudos Brasileiros]" foram o nascedouro da supervisão, principalmente com as reformas educacionais iniciadas com a implantação da LDB - Lei de Diretrizes e Bases - e as reformas de 1971.

A primeira Lei de Diretrizes e Bases no país, a Lei 4.024, de 20 de dezembro de 1961, tramitou por treze anos no Congresso até ser aprovada e, devido a essa demora em sua implantação, já no início da década de 1970, apresentava omissões ou formulações consideradas ultrapassadas para o novo momento da educação brasileira, ou seja, a referida lei não atendia mais aos anseios de um período da história que vislumbrava o desenvolvimento industrial e o rápido crescimento econômico, principalmente, pelas alianças desenvolvimentistas norte americanas, que tanto influenciaram nesse período. Assim,

${ }^{7}$ O PABAEE (Programa de Assistência Brasileiro-Americana ao Ensino Elementar) foi um programa criado pelo convênio do Ministério da Cultura, o Governo de Minas Gerais e a USOM do Brasil, United States Operation Mission to Brazil, em 22 de junho de 1956, tendo por objetivo central a melhoria do ensino elementar brasileiro, que depois chega a São Paulo pelo SEC.

${ }^{8}$ A Lei Complementar n ${ }^{\circ} 114$, de 13 de novembro de 1974, que institui o Estatuto do Magistério Público de $1^{\circ}$ e $2^{\text {o }}$ graus, define como especialistas no quadro do magistério o orientador pedagógico, o Diretor de Escola e o Supervisor Pedagógico, caracterizando, assim, o caráter técnico pedagógico. Essa mudança compunha a Reforma Administrativa da Secretaria da Educação iniciada em 1973, em função da própria reforma do ensino de 1971.

${ }^{9}$ O ISEB foi criado pelo Decreto $\mathrm{n}^{\mathrm{o}}$ 37.608, de 14 de julho de 1955, como órgão autônomo do Ministério da Educação e Cultura. 
buscava-se formar rapidamente a mão de obra para alavancar o progresso, mas a estrutura da escola brasileira contida na LDB apoiava-se em quatro graus escolares "superpostos e não integrados", que eram o primário, ginasial, colegial e superior, sendo que do primário ao curso ginasial havia a barreira do exame de admissão, além do vestibular entre o colegial e superior. Esse modelo acabava por definir a estratificação social que não se podia mais admitir frente à necessidade de recursos humanos (BOYNARD; GARCIA; ROBERT, 1971).

É preciso destacar, que a reforma educacional trazida em 1971, tinha como contexto político ideológico o regime militar, materializado na concepção de educação marcada pelo nacionalismo e pelo tecnicismo, cujo objetivo era o fortalecimento de uma educação mais rápida para o ingresso no mercado de trabalho $\mathrm{e}$, consequentemente, cada vez menos academicista, assim, acentuava a precarização da educação que oferecia aos privilegiados uma educação propedêutica e, ao proletariado, um ensino instrumental para servir ao mercado e ao desenvolvimento da nação. Os militares defendiam também, que a educação valorizasse a moral cristã, fundamentada na educação moral e cívica, pois consideravam ser fundamental para restabelecer a ordem no país e ainda vislumbravam uma nação rumo ao desenvolvimento aos moldes norte americano, por isso se buscava formar pessoas aptas a atender o mercado com obediência e domínio técnico, para isso era preciso cuidar da educação ampliando-a, implantando um currículo com conteúdos que atendessem a objetivos bem definidos e, finalmente, preparasse os professores para a implantação de uma educação moderna e promotora do desenvolvimento, todos esses pilares visavam também, a superação dos elevados índices de reprovação escolar no ensino primário.

\section{O percurso de investigação.}

A base dessa pesquisa documental são os registros escolares pertencentes à Escola Estadual Dr. Clybas Pinto Ferraz localizada em Assis, interior de São Paulo, que abrigou a partir de 1964 a sede do primeiro Ginásio Estadual do município, criado na década de 1930. Esse acervo apresenta em sua amplitude, documentação referente a organização das escolas isoladas, dos antigos grupos escolares e ginásios, bem como das escolas estaduais que tiveram seus prédios doados ao município, entre os anos de 1998 e 2000, com a política de municipalização.

Esses materiais nos possibilitam uma aproximação ao modo como se realizava a educação pública estadual e municipal e constituem parte de um vasto acervo que ainda se mantém como documentação primária. Nele evidencia-se aspectos da implantação do "novo 
currículo" e a organização das formações pedagógicas dos professores no período da reforma do ensino na década de 1970.

A escolha pelo recorte de 1970 a 1976 ocorre pela publicação da Lei no 5.692/1971, que fundamenta a reforma do ensino de $1^{\circ}$ e $2^{\circ}$ graus no país e sua implantação no estado de São Paulo que ocorreu em 1973.

Para a realização dessa pesquisa foram analisadas as Reuniões Pedagógicas encontradas em livro de Atas destinados ao registro dessas reuniões com os professores das Escolas Isoladas, Estaduais e Municipais, do município de Assis. As reuniões, até 1974, eram presididas por um inspetor escolar e por um inspetor auxiliar vinculados à Delegacia Regional do Ensino Elementar de Assis e essa era uma prática realizada por todo o estado, como descreve Mitrulis (1993, p. 40)

Mensalmente os Professores de Escola Isolada reuniam-se na sede da Inspetoria Auxiliar com o Inspetor Escolar e o Auxiliar de Ensino. Era o dia da Reunião Pedagógica. Em geral coincidia com o dia em que o Professor recebia seus vencimentos.

Os inspetores e os auxiliares tinham como uma das atribuições a responsabilidade por orientar a formação docente. Assim, no decreto ${ }^{10}$ que define suas atribuições tem-se, entre outras funções, a de "reunir mensalmente os professores de escola isolada do munícipio, para orientá-los e prestar-lhes assistência técnica”, o que era cumprido, como pode ser observado nas referidas atas. A sede das reuniões pedagógicas para orientação desses professores era o Grupo Escolar "Lucas Tomaz Menk”, em Assis.

A organização e o contexto no qual as reuniões pedagógicas aconteciam, bem como as mudanças trazidas pela legislação, foram compondo o panorama do currículo e delineando a formação de professores em plena Ditadura Militar nas escolas públicas paulistas.

As atas registram as vozes que ecoavam nas reuniões pedagógicas, e é por meio desses discursos que realizamos uma análise transnacional dentro dos estudos da história da educação.

Vidal (2020, p. 10), ao definir essa abordagem nos remete a definições que iniciam com a formação do Estado-Nação e o conceito de território, pois é esse um espaço delimitado pelas fronteiras que, em suas palavras, são o "limite entre o "nós" e o "eles", barreira física e simbólica a separar os de dentro dos de fora". Desse modo, os espaços constituem-se em meio à multiplicidade de vozes que, com suas histórias, fazem emergir ideias que denunciam a impossibilidade de homogeneidade, pois essas vozes nos contam sobre práticas 
"materializadas em sujeitos e artefatos, como condições de multiplicidade e da simultaneidade de histórias em territórios".

E, assim, Vidal, 2020, p. 11 explica a pertinência dessa

[...] abordagem da história transnacional da educação, na medida em que ela guarda, no seu próprio nome, a remissão à Nação e, por conseguinte, à delimitação das fronteiras e à territorialização plana historicamente constituída. O primado é epistemológico e se aplica tanto à história quanto à educação. No que concerne à história, vale destacar que a disciplina se produz como ciência no contexto da construção dos Estados-Nação, com íntimas ligações com o debate de temas em torno do nacional.

As marcas territoriais impostas pelo Estado visam imprimir certa homogeneidade, no entanto, a circulação de pessoas e ideias acaba por promover influência mútua entre os de dentro e os de fora. Assim, quando analisamos a formação de professores conduzidas pelos Inspetores Escolares temos nos registros das atas, evidências de que as práticas e discursos locais dialogavam com ideias para além de suas fronteiras, remetendo a uma dimensão mais ampla.

Ao retomar o conceito e a formação do Estado-Nação, Bourdieu (2014, s/p) nos adverte que o Estado é uma ilusão, é uma entidade que existe pela crença, não é portanto, um sujeito, mas personifica-se como na figura de, por exemplo: “um inspetor do ensino primário que vai visitar uma escola. Ele tem de cumprir um ato de um tipo perfeitamente particular: vai inspecionar. Representa o poder central. [...] tem uma autoridade que habita sua pessoa."

O Estado é um campo de poder, "isto é, um espaço estruturado segundo oposições ligadas a formas de capital específicas, interesses diferentes" e que exerce uma autoridade simbólica e, nesse campo de relações de poder, buscamos compreender como as ideias circulam e influenciam-se mutuamente considerando, principalmente, os professores em formação pedagógica orientada pelos inspetores escolares, cujo modelo de autoridade fora desenhado nos acordos do Brasil com os Estados Unidos.

Segundo Vidal (2020, p. 26) as pesquisas, numa abordagem transnacional da educação, nos ajudam a pensar essa circulação de

[...] ideias, saberes e modelos pedagógicos a partir de uma noção das fronteiras geopolíticas e o paradigma da transferência, ao trazer à tona as permeabilidades existentes nas trocas sociais, políticas, econômicas e culturais. 
As fontes primárias registram o espaço-tempo em que práticas de formação docente ocorriam, como ocorriam e quais sentidos podem ser apreendidos. Além disso, quais foram as ideias que influenciaram tais práticas são questões norteadoras dessa pesquisa.

\section{Reuniões Pedagógicas: a formação de professores por inspetores escolares}

Os registros das atas das reuniões pedagógicas analisadas seguem um padrão na sua organização, tanto nos aspectos administrativos e organizacionais, quanto nos aspectos pedagógicos, sempre conduzidos por um inspetor escolar.

Os aspectos administrativos discutidos no início de cada reunião, quase todas no último dia do mês ou no primeiro dia útil do mês seguinte, eram presididas pelo Inspetor que "recolhia os resumos mensais referentes ao mês em curso", como registrado em todas as atas. Os resumos eram relatórios de frequência dos alunos e dos professores das escolas isoladas que deveriam ser entregues ao inspetor para que providenciasse os devidos apontamentos na Delegacia de Ensino Elementar, tanto para acompanhamento da vida escolar dos alunos, quanto para elaboração da folha de pagamento dos professores. Entre as questões administrativas os inspetores também se incumbiam da organização da vida funcional dos professores, como observado:

A seguir o senhor inspetor deu o seguinte aviso: as substitutas que ingressarem deverão entregar os livros de escrituração no dia em que deixarem a escola. Disse ainda que deverão arrumar uma pasta e todos os atestados de tempo de serviço para fins de adicional. Foi pedido ainda para as substitutas CR\$1,00 (hum cruzeiro) para pagar a fôlha de pagamento. Foi avisa, digo, pedido aos professôres efetivos que trouxessem o $n^{o}$ do $R G$ para fins de conferição (Ata de 31/08/1970).

Mas na maior parte das atas, encontra-se a distribuição de atividades administrativas de responsabilidade dos inspetores para serem cumpridas pelos professores, como por exemplo:

Em seguida o sênhor inspetor orientou sôbre a solicitação feita pelo D.O. [diário oficial] sôbre o levantamento de matrículas do primeiro ano para o próximo ano letivo. Nesse levantamento deverão constar os alunos com sete anos completos e os que irão completar até trinta e um de dezembro de um mil novecentos e setenta e um (Ata de 30/09/1970).

E, na ata de 30/11/1970, está registrado:

[...] O sênhor inspetor distribuiu a seguir fôlhas para o material, digo, para o inventário do material existente na escola. O material da escola de origem 
particular deverá ser anotado numa fôlha separada. A seguir deu-nos uma farta explicação de como se deverá proceder a Avaliação Final. Somente o segundo e quarto anos deverão submeter-se aos exames finais. Nos demais graus deverá ser feita uma avaliação para controle de classificação. Os papéis à serem apresentados no próximo dia catorze são os seguintes: inventário - cadastro - quadro de exames - têrmo de exames e escrituração completa dos livros. [...] (Ata de 30/11/1970 - grifo nosso) ${ }^{11}$

Observa-se o volume de atividades administrativas que os inspetores incumbiam aos professores das escolas isoladas, principalmente no registro dos "papéis" que deveriam ser providenciados para a reunião seguinte, descritos nessa ata, um a um, separados por traços, conferindo-lhes destaque. Além disso, registra-se enfaticamente a forma como os inspetores cuidavam para que tudo fosse cumprido, a ponto de ser uma "farta explicação", conforme registrou a professora ao secretariar a reunião.

Segundo Mitrulis (1993, p. 40)

[...] tradicionalmente, as Reuniões Pedagógicas foram conhecidas por serem mais administrativas que realmente pedagógicas. Via de regra se tem a imagem das Reuniões Pedagógicas como mais um momento de controle burocrático do professor.

Como observado, os depoimentos corroboram a descrição trazida pela autora.

No que concerne à organização pedagógica, cabe destacar que os inspetores traziam especialistas a cada reunião para orientar os professores em relação aos conteúdos determinados pelos setores de orientação pedagógica (SOP).

A criação do SOP oficializou-se em 1966 junto à Chefia do Ensino Primário da Secretaria de Estado da Educação, “com o propósito de renovação educacional nas escolas comuns da rede oficial e com assistência direta e contínua” (MITRULIS, 1993, p.160).

Antes de descrever os aspectos pedagógicos encontrados nas atas, é importante esclarecer o papel dos Inspetores Escolares que, antes mesmo da oficialização do SOP, foram preparados para o controle direto da formação dos professores, como descreve Mitrulis (1993, p. 166):

Até o final de 1965, os Inspetores Escolares receberão uma atenção particular da Chefia do Ensino Primário, interessada em fazer dessa classe de profissionais efetivos elos de ligação entre as equipes do SOP, produtoras de orientação e planos de unidades didáticas e de material de apoio pedagógico, e as práticas de ensino no âmbito de cada sala de aula. Os Inspetores serão

${ }^{11}$ Nesse período, devido aos elevados índices de reprovação, reorganizaram o ensino em níveis I e II, cada qual com dois anos, assim, na passagem da $1^{\mathrm{a}}$ para a $2^{\mathrm{a}}$ série, pertencentes ao nível $\mathrm{I}$, não havia reprovação, assim como da $3^{\mathrm{a}}$ para a $4^{\mathrm{a}}$ série, que compunham o Nível II. Os exames finais, dessa forma, só eram aplicados aos alunos da $2^{\mathrm{a}}$ e $4^{\mathrm{a}}$ série.

RPGE- Revista on line de Política e Gestão Educacional, Araraquara, v. 25, n. esp. 4, p. 1962-1980, dez. 2021. e-ISSN: 1519-9029 DOI: https://doi.org/10.22633/rpge.v25iesp.4.15934 
orientados no sentido de entenderem suas funções como de supervisão administrativa e supervisão pedagógica $[\ldots]$

O SOP foi regulamentado pela Portaria n 79 de 16 de junho de 1966, que expandiu os serviços para as sedes das Delegacias de Ensino Elementar do Estado, com a implantação dos Setores Regionais de Orientação Pedagógica (SEROP) e estabeleceu suas atribuições, entre elas, o desenvolvimento de atividades e treinamento para as escolas primárias, sob a supervisão da inspetoria.

Segundo Silva Jr. (1984, p. 59), o resultado do trabalho dos setores regionais foi considerado pelos responsáveis da Secretaria de Estado da Educação, como positivo e isso "gerou a convicção da validade de sua sistematização e institucionalização", o que levou a ampliação desse serviço, em 1968, com a instituição do Setor de Assistência Pedagógica $(\mathrm{SAP})^{12}$ e os Setores Regionais de Assistência Pedagógica (SERAP) junto às inspetorias regionais de ensino normal e secundária. Observa-se que ao atender as escolas normais, o Estado estaria formando os futuros professores dentro da política que estava sendo elaborada. Esse movimento voltado à assistência pedagógica visava unificar o currículo que se estava desenhando para a formação das professoras primárias no curso normal.

Nesse período havia duas Delegacias de Ensino, uma que cuidava do ensino elementar e, outra que cuidava do ensino normal e secundário, incluindo-se o ensino profissional, justificando a existência de dois setores pedagógicos distintos, o SEROP e o SERAP.

Nas atas das reuniões pedagógicas há o registro do treinamento mensal realizado por professores especialistas, a pedido do inspetor. A proposta de formação era claramente unilateral na medida em que o especialista do SEROP oferecia o conteúdo por meio da apresentação de modelos organizados que eram trazidos por ele, e que, segundo os registros, deveriam ser seguidos pelos professores. É possível identificar, como isso acontecia, conforme ata da reunião de 03/04/1971:

[...] A seguir iniciou-se o estudo de algumas apostilas elaboradas pelo SEROP de Assis, sôbre planos de aula de leitura do nível I e II. Sôbre o primeiro ano do nível I, foi-nos apresentado um plano "modelo" de leitura estoriada, para ser por todos executados. Um aspecto interessante do plano: "o professor deverá ter confeccionado previamente, em álbum seriado, uma seqüência de gravuras de acôrdo com a estória a ser dada". Foi-nos ainda fornecida uma série de sugestões de atividades relacionadas à leitura. Sôbre o segundo ano do nível I, terceiro e quarto do Nivel II, o plano de leitura refere-se a um poema com todos os passos básicos e vem acompanhado de um plano suplementar como atividade relacionada. É também "modelo" $e$

${ }^{12} \mathrm{O}$ Ato $\mathrm{n}^{\circ} 289$, de 18 de outubro de 1968 cria o SAP e o SERAP em todas as inspetorias e Delegacias Regionais de Ensino Secundário e normal. 
deverá ser aplicado por todos os professores. Depois dos comentários feitos chegamos à conclusão de que êstes documentos são de grande valia no desenvolvimento da leitura, e que executados serão de bastante aproveitamento para o aluno (grifo nosso).

Os modelos, segundo o registro, seriam de bastante aproveitamento para o aluno, mas observa-se que o foco naquele momento é de um ensino apoiado em instrução programada, por meio da qual desenvolvia-se passos sequenciais acerca da estrutura da língua, como nesse exemplo. E, como destacado, os modelos deveriam ser aplicados por todos os professores. No entanto, há nesse discurso um aspecto que chama a atenção, a palavra modelo colocada entre aspas e, na sequência, a declaração de que o tal modelo deveria ser seguido por todos, ainda que destacassem ser apenas um modelo. Tal destaque entre aspas parece mostrar certa ironia da professora que secretariou essa reunião diante da clara intenção de um discurso monológico de silenciamento. Frente às determinações pedagógicas, só restava o cumprimento destas, pois nessas reuniões não há registros de um momento sequer para os professores socializarem suas experiências ou discutirem as dificuldades enfrentadas no cotidiano de suas salas de aula, tão solitárias nas escolas isoladas. Em uma outra ata, de 02/10/1976, corroborando essa ideia, registra-se:

O prof. Dirceu lembrou ainda que os Guias Curriculares trazem os temas e o professor deverá dosar a profundidade da matéria de acordo com sua classe. Todos os temas devem ser atacados, mesmo que de leve. [...] A professora Aparecida [...] opinou que ultimamente tem-se dado muita importância a papéis e que a essência do ensino está sendo esquecida. A professora Claudete [...] sugeriu que se aproveitasse a capacidade de alguns professores no sentido de que em cada reunião um deles desse sugestões de atividades. [...] (grifo nosso).

As professoras corajosamente, num ato de resistência, posicionaram-se contra o volume de conteúdos que lhes era oferecido nas orientações pedagógicas com os guias curriculares que, ao que parece, não atendiam ao que a professora considerou como a essência do ensino. Destaca-se que o ato de resistência das professoras só aparece nas atas de 1976, momento em que as reuniões pedagógicas eram conduzidas por supervisores. Há ainda a sugestão de que fosse dado a elas o controle da ação docente na preparação das atividades de ensino. Nessa ata não se observa registro de que tais sugestões tivessem sido acatadas, tão pouco nas seguintes, ao contrário, essas acabaram atropeladas pelas solicitações dos supervisores, que eram a personificação do Estado no exercício de sua autoridade. 
Essa autoridade fazia-se necessária para a implantação da Reforma de Ensino de $1^{\mathrm{o}} \mathrm{e}$ $2^{\circ}$ graus em São Paulo, como disposto no artigo $72^{13}$ da lei 5.692/1971, que determinava a implantação da reforma gradativamente com a elaboração de um plano estadual e esta reforma trazia mudanças significativas na organização da educação escolar, como descreve Ferraz:

[...]tornou-se imperativa a formação, em novas bases, dos professores e especialistas da educação, assim como obrigatório seu constante aperfeiçoamento e atualização; [...] transferiram-se para os sistemas locais todos os encargos de fiscalização dos estabelecimentos de ensino de $1^{\circ}$ e $2^{\circ}$ graus, particulares e municipais (FERRAZ, 1983, p. 65)

As mudanças propostas na reforma exigiriam a formação de professores dentro do currículo imposto e, certamente, a função fiscalizadora dos supervisores representava o tom dessa implantação.

Com a implantação de um currículo inovador, como defendido pelo acordo Aliança para o Progresso ${ }^{14}$, de materiais didáticos que pudessem ser reproduzidos e do controle de sua implantação, o que antes era feito pelos inspetores escolares, continuaria a ser realizado pelos supervisores. Essa proposta, que se assentava na mera reprodução de modelos, ao ser aplicada, fez com que a orientação técnica se sobrepusesse aos saberes da prática pedagógica dos professores.

Nos registros analisados ao longo de 1970 a $1973^{15}$ as orientações eram realizadas por especialistas em Língua Pátria, Matemática e Educação Moral e Cívica e Ciências, mensalmente e sob a presidência de um inspetor. Os especialistas do SEROP ofereciam os modelos e treinavam os professores sobre como tais modelos deveriam ser reproduzidos nas salas de aula das escolas isoladas. Ao inspetor, como descrito em suas atribuições, cabia o acompanhamento e a fiscalização a fim de garantir que esses conteúdos chegariam aos alunos, o que aparece enfaticamente em todas as atas.

A imposição e controle exercido pelos Inspetores Escolares na aplicação do currículo aparece nas atas com ênfase à obrigatoriedade, como pode ser observado na ata de 30/04/1970

13 Art. 72. A implantação do regime instituído na presente Lei far-se-á progressivamente, segundo as peculiaridades, possibilidades e legislação de cada sistema de ensino, com observância do Plano Estadual de Implantação que deverá seguir-se a um planejamento prévio elaborado para fixar as linhas gerais daquele, e disciplinar o que deva ter execução imediata.

14 A Aliança para o Progresso é a denominação do programa de assistência econômica no qual os Estados Unidos disponibilizariam 20 bilhões de dólares para a promoção do desenvolvimento econômico dos países latino-americanos tendo como exigência, entre outras, a implantação de processos inovadores na educação, o que se traduz como o fortalecimento da educação tecnicista.

${ }^{15}$ Em 1973, com a reforma do ensino no Estado de São Paulo, os SEROPs foram extintos. 
O senhor Inspetor logo em seguida deu uma ligeira orientação sobre as Aulas de Educação Moral, Social e Cívica que deverão ser ministradas obrigatoriamente duas vezes por semana, cuja publicação saiu no D.O. do dia vinte e cinco e vinte e seis de março próximo passado.

Há, ainda, registros mais enfáticos que destacam esse controle de forma autoritária e ameaçadora como em 31/10/1970:

O senhor inspetor deu-nos o seguinte aviso sôbre a falta de comparecimento ao trabalho: o professor deverá comunicar sua falta imediatamente, quer dizer, no primeiro dia de volta ao serviço. Disse ainda que o professor deverá permanecer na escola durante o periodo inteiro mesmo que não haja alunos. Lembrou-nos também que a autorização para viajar é dada em condições precárias podendo ser caçada desde que haja prejuizo para o ensino. Avisou-nos do Programa de Educação Moral e Cívica que deverá ser dado pois haverá pessoas autorizadas que percorrerão as escolas afim de verificarem se estão sendo dadas as aulas de acôrdo (Ata 31/10/1970, p. $4 \mathrm{v})$.

Esse tom ameaçador está presente nas atas em diferentes situações ligadas à reprodução de um currículo alienante, organizado em instrução programada cujo discurso se justificava pela necessidade de se combater os elevados índices de repetência, uma vez que era essa a contrapartida do país na Aliança para o Progresso.

Em São Paulo, as Delegacias de Ensino Elementar foram guardiãs dessa missão, pois como descreve Ferraz (1983) havia o compromisso dessa unidade federada na implantação da reforma.

A ideologia desenvolvimentista pregava a modernização, cujo modelo imposto pelos norte-americanos estava impresso nos materiais e orientações pedagógicas que representavam a solução para os problemas de fracasso escolar registrados na reprovação dos alunos do ensino primário. Com a ampliação da escolarização para oito anos e a publicação da Reforma do Ensino em São Paulo, começa o desmonte dessa estrutura, com a extinção dos SEROPs para a implantação da Diretoria de Assistência Pedagógica responsável pelos Guias Curriculares que se apresentavam como uma determinação central por sua inovação, estes seguiam as orientações federais em concepção técnica de currículo, fazendo com que o Movimento da Tecnologia Educaciona ${ }^{16}$ fosse fortalecido.

${ }^{16} \mathrm{O}$ movimento da Tecnologia Educacional trazido na bagagem dos acordos MEC-USAID incorporava o uso de recursos audiovisuais e de comunicação de massa visando ampliar a eficiência do ensino, caracterizado pela visão sistêmica de educação. 
E esse modelo acabou por impulsionar a extinção das escolas isoladas ${ }^{17}$, juntamente com as demais escolas rurais, pois, como escolas desprestigiadas, não atendiam às novas exigências educacionais, era preciso mudar as práticas, uma vez que os objetivos haviam mudado. A sua extinção ocorreu quando os recursos para o transporte dos escolares da zona rural foram previstos em lei, o que só ocorreu com a publicação da Lei 9.394 de 20 de dezembro de 1996, a LDB, pós Constituição de 1988.

\section{Considerações finais}

Os livros de atas, inicialmente pareciam registros frios de fatos ocorridos em reuniões pedagógicas, contudo, na análise, as vozes dos professores e inspetores emergiram. O modo com que os professores registraram os fatos, muitas vezes utilizando-se de sinais gráficos que enfatizavam determinadas situações e, em outras pela escolha de verbos como "dever" associado a todas as determinações dos inspetores, nos possibilitaram compreender como se fazia cumprir o que estava retratado na legislação. As palavras, nunca neutras, evidenciam a ideologia dominante, o que pode ser confirmado nos atos legais e em pareceres oficiais que submetem a formação docente a interesses econômicos delineados pela visão norte americana de modernidade. O contexto autoritário é revelado no discurso escrito, assim como a forma de resistência daqueles que se viam desqualificados como profissionais, pois eram submetidos a reprodução de materiais que, na perspectiva deles, desviavam-se da essência do ensino. E foi nesse discurso local que pudemos, por conseguinte, destacar o peso da ideologia que definia a educação nacional no momento em que os militares firmaram acordos "optando por um desenvolvimento associado, comandado por grupos internacionais localizados majoritariamente nos Estados Unidos" e que permitiram a entrada de capital para a implantação do poder militar em território nacional (COSTA, 2004, s/p).

O Estado militarizado, com feição autoritária, recebeu investimentos que financiariam o desenvolvimento econômico e, consequentemente, a soberania, ou pelo menos a ideia de domínio de suas fronteiras. Contudo, pela fluidez das fronteiras ideológicas a soberania não estava sendo preservada, principalmente porque os investimentos exigiam, na contrapartida, a intervenção no campo educacional com reformas que iam do ensino primário até a formação de professores do Ensino Médio. A Educação é, pois, o território de uma nação, por isso

${ }^{17}$ Em 1971 havia em São Paulo 15.064 escolas isoladas, dividida em 8.318 escolas comuns e 6.746 escolas de emergência. 
quando esta é delineada por princípios outros, a invasão silenciosa acaba por destruir a maior riqueza do Estado.

A fronteira entre a educação nacional e a norte americana, não em termos geográficos, mas ideológicos, moldaram o papel de especialistas com a finalidade de controlar e fiscalizar a implantação dos modelos impostos, pois dessa forma atenderiam aos interesses do poder hegemônico que se alastrava por toda América Latina.

O conceito de formação observado nas vozes desses sujeitos era definido pelo ato de "dar forma, de moldar" o profissional dentro dos preceitos legais, e isso ocorreu com professores que tiveram ceifada a sua autonomia e, também, com os inspetores que incorporaram, na orientação técnica, a personificação do Estado fiscalizador, o que se fez presente na alteração da inspetoria à supervisão e que tem se perpetuado até os dias atuais, como pode ser confirmado na legislação ${ }^{18}$ vigente.

AGRADECIMENTOS: À FAPESP (Processo 2018/26699-4).

\section{REFERÊNCIAS}

BOURDIEU, P. Sobre o estado: cursos no collège de france (1989-92). São Paulo: Companhia das Letras, 2014.

BOYNARD, A. P.; GARCIA, E. C.; ROBERT, M. I. A reforma do ensino. São Paulo: LISA, 1972.

BRASIL. Lei n. 4.024, de 20 de dezembro de 1961. Fixa a Lei de Diretrizes e Bases da Educação Nacional. Brasília, DF: Coleção de Leis do Brasil, 27 dez. 1961. v. 7. Disponível em: https://www2.camara.leg.br/legin/fed/lei/1960-1969/lei-4024-20-dezembro-1961353722-norma-pl.html. Acesso em: 09 out. 2020.

BRASIL. Lei n. 5.692, de 11 de agosto de 1971. Fixa Diretrizes e Bases para o ensino de $1^{\circ}$ e $2^{\circ}$ graus, e dá outras providências. Brasília, Df: Coleção de Leis do Brasil, 12 ago. 1971. v. 5. Disponível em: https://www2.camara.leg.br/legin/fed/lei/1970-1979/lei-5692-11-agosto1971-357752-norma-pl.html. Acesso em: 02 maio 2021.

COSTA, E. V. (org.). Globalização e reforma universitária: a sobrevivência do mec-usaid. In: BARBOSA, R. L. L. (org.). Trajetórias e perspectivas da formação de educadores. São Paulo: Unesp, 2004. cap. 2.

FERRAZ, E. F. Caminhos percorridos. São Paulo: Saraiva, 1983

${ }^{18}$ Decreto $n^{\text {o }}$ 64.187, de 17 de abril de 2019. Reorganiza a Secretaria da Educação e dá providências correlatas, que em seu artigo 74 define as atribuições da supervisão. 
MITRULIS, E. "OS ÚLTIMOS BALUARTES" Uma contribuição ao estudo da Escola Primária: as práticas de inspeção escolar e de supervisão pedagógica. 1993. $235 \mathrm{f}$. Tese (Doutorado em Educação) - Faculdade de Educação, Universidade de São Paulo, São Paulo, 1993. Cap. 5.

SÃO PAULO (Estado). Lei n. 9, de 22 de março de 1874. Estabelece o ensino primário obrigatório na província. São Paulo, SP: Coleção da Legislação Paulista, 22 mar. 1874. Disponível em: https://www.al.sp.gov.br/repositorio/legislacao/lei/1874/lei-922.03.1874.html. Acesso em: 09 ago. 2021.

SÃO PAULO (Estado). Lei n. 88, de 8 de setembro de 1892. Reforma a instrucção publica do Estado. São Paulo, SP: Assembleia Legislativa, 1892. Disponível em:

https://www.al.sp.gov.br/repositorio/legislacao/lei/1892/lei-88-08.09.1892.html Acesso em: 19 out. 2020.

SÃO PAULO (Estado). Lei n. 520, de 26 de agosto de 1897. Suprime o Conselho Superior de Instrução Pública e dá outras providências. São Paulo, SP, 31 ago. 1897. Disponível em: https://www.al.sp.gov.br/norma/64611. Acesso em: 05 jun. 2020.

SÃO PAULO (Estado). Decreto n. 1883, de 06 de junho de 1910. Reorganiza a inspetoria geral do ensino público. 1910. Disponível em: https://www.al.sp.gov.br/norma/135637. Acesso em: 08 abr. 2021.

SÃO PAULO (Estado). Lei n. 1750, de 11 de dezembro de 1920. Reforma a Instrução Pública do Estado. São Paulo: Assembleia Legislativa, 11 dez. 1920. Disponível em: https://www.al.sp.gov.br/norma/65983. Acesso em: 06 jun. 2021.

SÃO PAULO (Estado). Decreto n. 3.356, de 31 de maio de 1921. Regulamenta a lei n.1.750, de 8 de dezembro de 1920, que reforma a instrução pública. São Paulo, SP: Assembleia Legislativa, 1921. Disponível em:

https://www.al.sp.gov.br/repositorio/legislacao/decreto/1921/decreto-3356-31.05.1921.html. Acesso em: 19 out. 2020.

SÃO PAULO. Decreto n. 14542, de 16 de fevereiro de 1945. Fixa as áreas de jurisdição e as sedes das Delegacias Regionais do Ensino da Capital e do Interior. São Paulo, SP, 20 mar. 1945. Disponível em: https://www.al.sp.gov.br/norma/127310. Acesso em: 11 mar. 2020.

SÃO PAUlO (Estado). Ato n. 289, de 18 de outubro de 1968. Institui Setores Regionais de Assistência Pedagógica Junto às Inspetorias Regionais do Ensino Secundário e Normal. São Paulo, 19 out. 1968.

SÃO PAULO (Estado). Lei complementar n. 114, de 13 de novembro de 1974. Institui o Estatuto do Magistério Público de 1. ${ }^{\circ}$ e 2. ${ }^{\circ}$ graus do Estado. São Paulo, 1974. Disponível em: https://www.al.sp.gov.br/repositorio/legislacao/lei.complementar/1974/lei.complementar-11413.11.1974.html Acesso em 05/04/2021. Acesso em: 19 out. 2020.

SILVA JR, C. A. Supervisão da educação: do autoritarismo ingênuo à vontade coletiva. São Paulo: Loyola, 1984. 
SOUZA, R. F. Templos de civilização: a implantação da escola primária graduada no Estado de São Paulo: (1890-1910). São Paulo: Fundação Editora Unesp, 1998

SOUZA, R. F. Alicerces da Pátria: história da escola primária no Estado de São Paulo (1890-1976). Campinas, SP: Mercado das Letras, 2009.

VIDAL, D. G. (org.). Sujeitos e artefatos: territórios de uma história transnacional da educação. Belo Horizonte: Fino Traço, 2020.

\section{Como referenciar este artigo}

BARBOSA, R. L. L.; NICACIO, R. T. A orientação dos inspetores escolares na formação de professores no período de 1970 A 1976: um olhar sobre São Paulo. Revista on line de Política e Gestão Educacional, Araraquara, v. 25, n. esp. 4, p. 1962-1980, dez. 2021. eISSN:1519-9029. DOI: https://doi.org/10.22633/rpge.v25iesp.4.15934

Submetido em: 20/08/2021

Revisões requeridas em: 12/10/2021

Aprovado em: 15/11/2021

Publicado em: 08/12/2021 